\title{
El Bicentenario republicano del Derecho Penal peruano
}

\section{The Republican Bicentennial of Peruvian Criminal Law}

Javier Ysrael Momethiano Santiago* https://orcid.org/0000-0002-6009-1907

Daivi Emerson Farfán Sullcahuaman** https://orcid.org/0000-0003-1309-6593

http://dx.doi.org/10.21503/lex.v19i27.2250

* Abogado, Master en Derecho Penal, con estudios de doctorado en Derecho en la Universidad Nacional Mayor de San Marcos. Profesor universitario a nivel de pregrado y posgrado. Especializado en Destrezas de Litigación Oral por California Western School Of Law (USA). Perú.

Correo electrónico: momethianoabogados@yahoo.es

** Abogado, Licenciado en Educación, con estudios de maestría en Ciencias Penales y doctorado en Derecho en la Universidad Nacional Mayor de San Marcos. Profesor universitario de pregrado. Experto en Litigación Oral por la Universidad de Salamanca (Espańa). Perú.

Correo electrónico: dfarfans@gmail.com

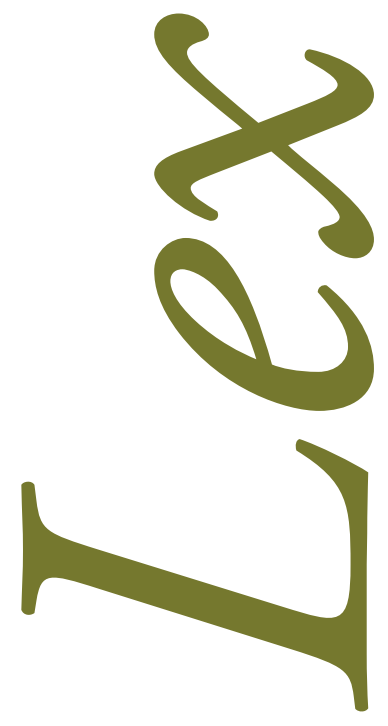




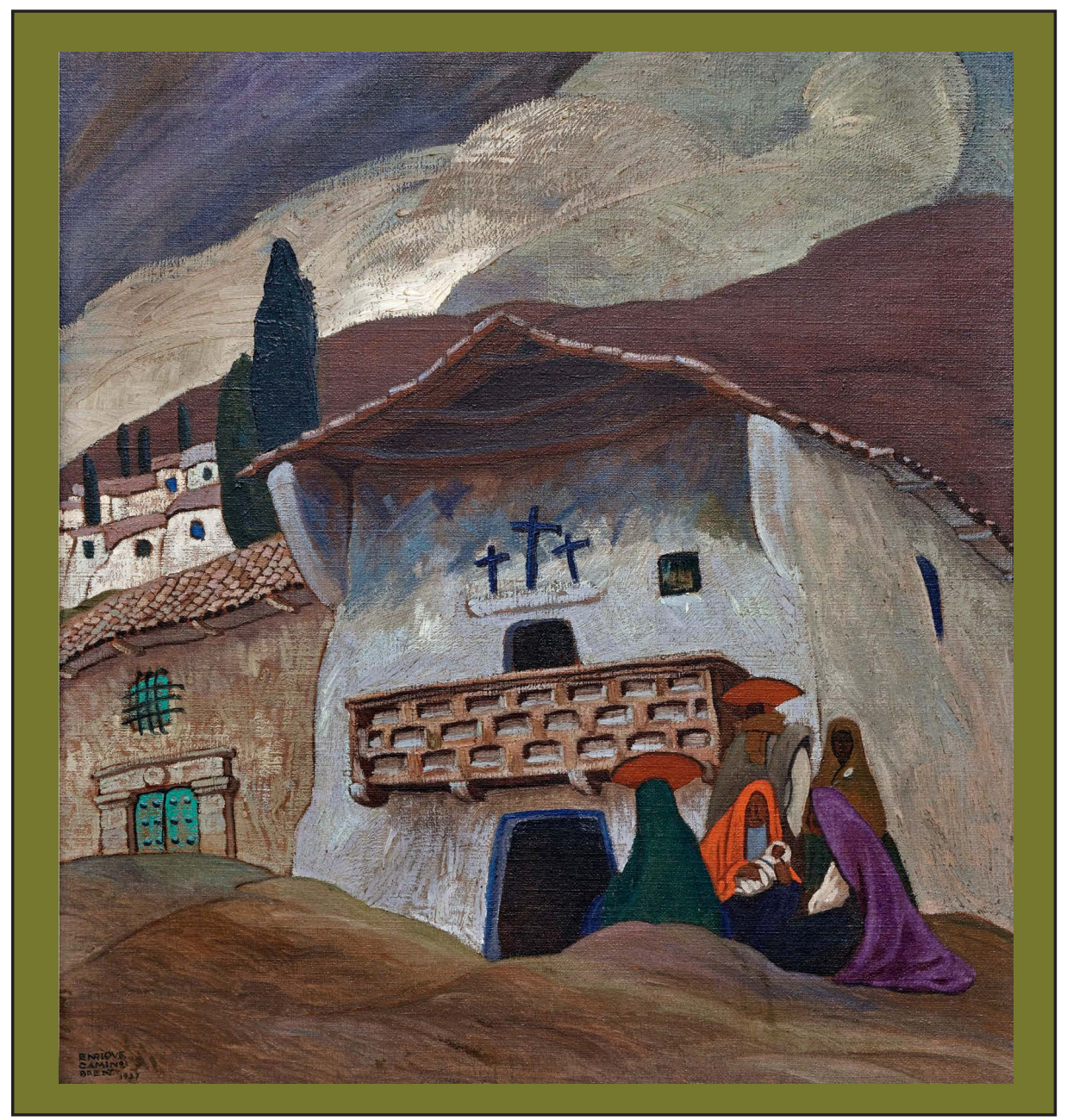

Balcón de Herodes. Enrique Camino Brent pintor peruano del indigenismo (Cajamarca 1909-1960). 


\section{RESUMEN}

El Bicentenario republicano del Derecho Penal peruano, es una mirada histórica de los comienzos, dificultades, proyectos y reformas de la legislación penal del Perú, apreciando su fundamento en el periodo prehispánico (Derecho Penal indígena), luego en el periodo hispánico (Derecho Penal indiano), continuando con la intervención de San Martin y Bolívar (Derecho Penal criollo) y finalizando con el periodo republicano (Derecho Penal nacional en el siglo XIX, cambios legislativos penales en el siglo XX, e impulsos por mejorar la legislación penal vigente en el siglo XXI).

Palabras clave: Derecho Penal indigena, Derecho Penal indiano, Derecho Penal criollo, Derecho Penal nacional.

\section{ABSTRACT}

The Republican Bicentennial of Peruvian Criminal Law, is a historical look at the beginnings, difficulties, projects and reforms of the criminal legislation of Peru, appreciating its foundation in the pre-Hispanic period (Indigenous Penal Law), then in the Hispanic period (Indian Criminal Law), continuing with the intervention of San Martin and Bolivar (Creole Criminal Law) and ending with the republican period (National Criminal Law in the 19th century, criminal legislative changes in the 20th century, and impulses to improve criminal legislation current in the 21 st century).

Key words: Indigenous Criminal Law, Indian Criminal Law, Creole Criminal Law, National Criminal Law. 


\section{INTRODUCCIÓN}

\section{LA NORMATIVIDAD PENAL DURANTE EL PERIODO PRE- HISPÁNICO E HISPÁNICO}

Las culturas del antiguo Perú comprende al Horizonte Temprano (apreciándose a la cultura Chavín, Paracas y Vicus), al Intermedio Temprano (abarcando a la cultura Nazca y Mochica), al Horizonte Medio (comprende a la cultura Tiahuanaco y Wari), y al Intermedio Tardío (apreciándose a la cultura Chimú, Chincha, Chanca, Pachacámac y Reino Aimara). El Perú preínca no conoció la escritura, puesto que no dejaron testimonios de oídas sobre la existencia del ámbito de punibilidad que los cronistas pudieran haber recogido.

El Derecho Penal indígena es un conjunto de normas consuetu $\neg$ dinarias: Ama sua (no seas ladrón), ama llulla (no seas mentiroso), y ama quella (no seas perezoso), que tienen por finalidad tutelar la vida, la propiedad, el culto a la divinidad y la organización política preínca e inca ${ }^{1}$; a través de la prisión y la pena de muerte, aunque con trato diferenciado para aquel que realizaba sodomía ${ }^{2}$ y respecto al que asesinaba empleando veneno ${ }^{3}$, pues su riesgo de propalarse exigía el endurecimiento de las sanciones, en la idea de primera velocidad del derecho penal ${ }^{4}$. Entonces, en el sistema jurídico incaico imperaba la lex non scripta, pues la palabra del Inca era fuente de ley ${ }^{5}$. Asimismo, existieron antecedentes de represión penal económica, como la pena de azote al cacique que ocultara indios en censos para variar la carga tributaria, (ilícito tributario inmediato), y la prohibición de matar ganado hembra (ilícito tributario mediato).

1. Jorge Basadre, Los fundamentos de la historia del derecho, (Lima: Editorial Universitaria, 1967), p. 199

2. El Inca Garcilaso de la Vega, Comentarios reales. "El origen de los Incas", (Barcelona: Bruguera, 1968), pp. 235 y 236.

3. Felipe Guamán Poma de Ayala. Nueva crónica y buen gobierno, 2018. Link:

http.//www.latinamericastudies.org/incas/Nueva_coronica_l.pdf., p. 222.

4. Al respecto, expediente del Archivo de Indias de 1558, AGI, justicia 41, María Rostworowski de Diez Canseco, Historia del Tahuantinsuyu, (Lima: Instituto de Estudios Peruanos, 2014), p.218.

5. Miroslav Stingl, El imperio de los Incas, Esplendor y decadencia de los hijos del sol, (Buenos Aires: Losada, 2013), p. 243 
La expresión indígena ha sido utilizada desde la conquista para ofender a los runas andinos o grupos que luchan por tener una identidad sociocultural, pues la conquista no solo fue un impacto físico, plasmado en la disminución de la población nativa y la su-perioridad tecnológica, sino también una confrontación social y cultural desigual ${ }^{6}$.

La conquista tuvo lugar en Cajamarca con la captura y muerte del Inca Atahualpa, el 26 de julio de 1553. Luego los españoles e indígenas que los apoyaban ocuparon el Cuzco, el 14 de noviembre de 1553, exigiendo el invasor que Manco Inca gobierne, aunque al darse cuenta éste, que los españoles ambicionaban el oro y plata, se rebeló contra éstos. Siendo derrotado Manco Inca, se fue a Vilcabamba. Los Incas de Vilcabamba resistieron hasta la captura de Túpac Amaru I, en 1572.

"La incorporación de la sociedad andina al sistema socioeconómico foráneo, estableció la variación del proceso cultural indígena. La raza india sometida a los conquistadores en condiciones discriminatorias tuvo como secuela un proceso de destrucción de las estructuras de la sociedad indígena (desarticulación de las relaciones sociales, económicas, políticas y religiosas) dando origen jurídico a la República de indios (República explotada), aunque gobernados por una sociedad hispana (República dominante) como legado. Desde inicios del siglo XIX se ha sostenido que los principios del Derecho Penal deben ser apoyados por el derecho natural o absoluto, pues la escuela clásica surgió para contrarrestar al antiguo régi $\neg$ men del derecho, que se apoyaba en la tortura, la pena de muerte, las acusaciones secretas y toda manera de sometimiento. A pesar de esto, nuestros juristas no le dieron el interés necesario al campo penal en los comienzos de la República, y entrada esta, cultivaron un saber foráneo de Derecho Penal, dejando de lado las iniciativas del Derecho Penal patrio. Con ello enfocaron la carencia de auto determinación del indígena, lo cual sustentaba su marginación"”.

El Derecho Penal indiano se da a partir de que los indios eran tratados como animales o seres sin alma, es decir, como objetos y no sujetos de derecho. La naturaleza humana del indio fue considerada por Paulo III, en la bula Sublimis Deus, aunque esta les daba una personalidad jurídica restringida (capacidad disminuida del indio que estaba bajo la tutela de una persona capaz), puesto que sus derechos fueron desconocidos y tan solo eran sujetos de obligaciones (tesis colonialista). Dentro de la nueva sociedad dominante, los «indios» eran vasallos tributarios de la Corona Castellana, aunque estos eligieron evadir la fiscalización colonial; en tal sentido, de indios tributarios pasaron a transformarse en indios vagos y forasteros.

La legislación estableció que los derechos de los indios debían contener diferenciación y control, pues la nueva situación lo exigía en sus preceptos, ya que "durante el Virreinato, las leyes penales son

6. José Carlos Mariátegui. Siete ensayos de interpretación de la realidad peruana, (Lima: s.e.,1972), p. 56.

7. Javier Ysrael Momethiano Santiago. “El indígena en la dogmática penal del siglo XIX”, en: Lex, revista de la Facultad de Derecho y Ciencia Politica de la Universidad Alas Peruanas, número 10, año XI, Lima: Ediciones e impresiones Andina SAC, (2012): p. 309. 
drásticas y protegían básicamente a la Metrópoli. La aplicación era desigual. En este momento lo que se pretendía era lograr la mayor cantidad de ingresos para la Corona española, no importando las injusticias que se produjeran en la Colonia" ${ }^{8}$.

"El derecho de conquista se imponía como una sociedad de castas basada en la discriminación étni-

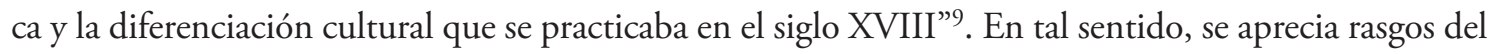
derecho penal de autor por la presencia de personas de raza negra en ciertas zonas de la ciudad y por solo tener $\operatorname{armas}^{10}$. En esta guerra de castas se aprecia que:

"los alzados supieron combinar la nostalgia del pasado prehispánico con la lealtad al rey español, por hipótesis ignorante de las inequidades que en su nombre se cometían en América, exacerbó las tensiones entre las castas peruanas; indios contra blancos y mestizos en el Bajo Perú; indios y mestizos contra blancos en el Alto Perú. En este sentido, más que ofrecer un antecedente para las luchas de independencia, estos alzamientos parecen proporcionar una de las claves para entender la obstinación con que [esta] área iba a apegarse a la causa del rey; una parte de la población nativa iba a ver en el mantenimiento del orden colonial la mejor defensa de su propia hegemonía, y en esta la única garantía contra el exterminio a manos de las más numerosas castas indígenas y mezcladas"11.

"Desde el virreinato de Toledo hasta que los Borbones llegan al trono, se organizó un sistema social y estatal que insertó a la comunidad nativa al Imperio (tesis indigenista). La concepción de las Leyes de Indias establecía un tratamiento de salvaguarda y a la vez marginativo de los indios, ya que se les consideraba seres incapaces, subordinados a la tutela del colonizador espańol con el propósito de percibir beneficios de la civilización y fe. Además, se consideraba a los indios como flojos, viciosos y que prontamente se olvidaban lo enseñado, ya que era una característica de su estatus cavernario o salvaje, al considerarlos incapaces, tomando en cuenta su desarrollo mental, grado cultural y costumbre ${ }^{12}$, a menos que se les diera la "conversión» que no solo abarcaba al ámbito religioso, sino que imponía un estilo de vida de los españoles conquistadores"13.

8. Luis Miguel Bramont-Arias Torres, Manual de Derecho Penal. Parte General, (Lima: Editorial Santa Rosa S. A. 2000.) p. 44.

9. Javier Ysrael Momethiano Santiago. op. cit., 310

10. Pedro de León Portocarrero, Descripción del Virreynato del Perú, (Lima: Editorial Universitaria de la Universidad Ricardo Palma, 2009), pp. 26 y 53.

11. Tulio Halperin Donghi, Historia contemporánea de América Latina, (Madrid: Alianza Editorial, Tercera edición, 1972), pp. 77-78.

12. Cfr.Germán Leguía y Martínez, Diccionario de la legislación criminal del Perú, (Lima: Librería e imprenta Gil S. A.), p. 472.

13. Javier Ysrael Momethiano Santiago. op. cit., p. 311. 
"La recepción de las leyes vigentes en una sociedad determinada a otra; implica aceptación cognoscitiva y conatíva de un derecho foráneo por parte del pueblo receptor, mientras que la imposición se da cuando a una comunidad se le conmina a obedecer y poner en práctica la legislación foránea” ${ }^{14}$.

"Lo esencial de aplicar un derecho penal foráneo es su unilateralidad y coacción, aunque no podemos decir que se trata de una simple aplicación de este derecho, dado que los espańoles encontraron a su llegada una cultura desarrollada, cuyo Derecho Penal tuvieron que tener en cuenta, como es el caso de las fuentes indirectas preíncas elaboradas en cerámica por la cultura Mochica, representando juicios y aplicaciones de penas ${ }^{15}$; y como fuente incaica se tenía el conocimiento jurídico dado por los cronistas e historiadores. En este periodo, el creador del derecho era el inca, pues su ley lo hacía conocer al pueblo por intermedio de los quipucamayoc y amautas; utilizando los refranes al carecer de escritura. Tampoco es una mera aceptación de un Derecho penal extranjero, porque los miembros de la sociedad nativa que fueron vistos como objetos de legislación, se resistieron al nuevo orden y hasta se rebelaron"16.

Por eso, el Derecho Penal indiano tenía fuentes primarias (Recopilación de Leyes Indias de 1680, Catálogo de Matraya de 1819, además las Ordenanzas de Intendencias, Ordenanzas de Toledo, y las Leyes Municipales) y fuentes supletorias (Fuero Juzgo de 649, Fuero Real de 1255, Siete Partidas de 1256, Ordenamiento de Alcalá de 1348, Ordenanzas de Montalvo de 1484, Leyes de Toro de 1505, Nueva Recopilación de 1567, y Proyecto Ovando de 1570).

Además, el 01 de junio de 1635 Gaspar Escalona y Agüero, abogado de la Real Audiencia de Lima, remitió su Proyecto de Código Peruano, con dedicatoria a don Lorenzo Ramírez de Prado, integrante del Consejo de indias, en razón a la situación desdichada de los indios, persiguiendo su protección, y solicitándole que haga como suyo lo elaborado, en caso resulte necesario. Se entiende que el Proyecto llegó al destinatario, pero encontrándose después en la Biblioteca del Colegio de Cuenca y que con el trascurso se ubicó en la Biblioteca del Palacio Nacional de Madrid. Este Proyecto normativo estableció el Libro Privilegial, el Libro Espiritual, el Libro Personal, y el Libro Patrimonial. En sus disposiciones destaca los delitos cometidos contra los indios, los que se ubican en el sexto privilegio del Libro Privilegial ${ }^{17}$.

Las injusticias determinaron el surgimiento de movimientos independentistas que se inició en la Selva Central por juan Santos Atahualpa en 1742; en el Cuzco por Túpac Amaru II en 1780; y en el Alto Perú por Túpac Katari en 1781. Otros intentos de independencia se dieron en la revuelta de

\section{Ibídem.}

15. Las personas dejadas en el desierto, tal vez servían para alimentar a los buitres, como secuela de aplicar las leyes punitivas, Vid. Luis Guillermo Lumbreras Salcedo. Pueblos y Culturas del Perú Antiguo, (Lima: Ediciones Copé, tercera edición 2019), p. 253.

16. Javier Ysrel Momethiano Santiago. op. cit., p. 311.

17. Javier Villa Stein. Derecho Penal. Parte General, (Lima: ARA Editores, 2014), p.112. 
Tacna de 1811 por Francisco Antonio de Zela ${ }^{18}$, la rebelión de Huánuco de 1812 por Juan José Crespo y Castillo, la segunda revuelta de Tacna de 1813 por Enrique Paillardelli y Julián Peñaranda; y la rebelión del Cuzco de 1814 por los hermanos Angulo y Mateo Pumacahua. También, se detuvieron las insurrecciones efectuadas por las juntas de gobierno ${ }^{19} \mathrm{de}$, Chile, Quito, y Buenos Aires en $1810^{20}$. Habiéndose deshecho los movimientos surgidos por los colonizadores españoles situados en el Perú, era indispensable que concurra la corriente libertadora del Norte y la del Sur.

\section{LA LEGISLACIÓN PENAL DURANTE LA INTERVENCIÓN DE SAN MARTIN Y BOLÍVAR EN EL PERÚ}

La independencia del Perú no significó la ruptura del sistema so $\neg$ cioeconómico consolidado en tres siglos de coloniaje, es decir, que la emancipación "no tuvo propagación social, ni cultural de amplia escala, ni el vigor suficiente para crear una conciencia nacional" 21 .

"La ruptura de las relaciones políticas con la metrópoli se produjo por las guerras emancipadoras, pero sin que se diera una variación relevante de las estructuras internas del país, situación está que se prolongó al siglo XX”22.

"Proclamada la independencia política del Perú, se construyó un intento de Derecho Penal nacional, pues San Martín consideró que era un crimen que el aborigen siguiera siendo degradado; en tal sentido, dispuso la abolición del pago de tributo por considerarse un cobro indebido o exacción ilegal; asimismo, extinguió legalmente la palabra «indio» por ser una ofensa, sustituyéndola por «peruanos» el 27 de agosto de 1821. Sin embargo, todo esto quedó en buenas intenciones, pues la crisis social y económica determinaron que se incumpla con el decreto en el mismo momento de su promulgación, aunado a esto, el poder del sector dominante permitió la ineficacia de la disposición legal en mención, el 28 de agosto de 1821; dando origen a la guerrilla indígena por no lograr su interés propuesto explicado supra”23.

18. Este acontecimiento fue conocido como el primer gritó de libertad de la independencia, el 20 de junio de 1811. Luego, Francisco de Zela fue capturado y se le siguió un proceso criminal, siendo José Gerónimo de Vivar y López Lisperguer su defensor, un ilustre letrado y catedrático de la época. El 19 de abril de 1815, se confirmó la sentencia condenatoria a Francisco de Zela, siendo recluido junto a su hijo José Manuel de Zela y Siles, que, teniendo diez años de edad, no soportó la dureza de la prisión, falleciendo en 1817.

19. Estas se inspiraron en la formación de la Junta de Sevilla, pues los españoles se rehusaban obedecer a José Bonaparte como nuevo rey.

20. La revolución de mayo, fue un suceso ocurrido entre el 18 al 25 de mayo de 1810, que determinó la caída del Virreinato del Rio de la Plata, sustituyéndolo por la Primera Junta de Gobierno, iniciándose el proceso de independización de la Argentina.

21. José Matos Mar. “Dominación, desarrollos y pluralismos en la sociedad y cultura peruana”; en: Perú actual (Sociedad y política), México, s.e., (1970): p. 24.

22. Javier Ysrel Momethiano Santiago. op. cit., p. 312.

23. Ibídem. 
"En este marco, la construcción de un Derecho Penal peruano (criollo) resulta una ficción pues aun cuando la elaboración jurídica correspondiera a los criollos cultos peruanos, estos eran producto de la educación europea, y la sociedad que el Derecho propuesto por ellos pretendía regular, estaba radicalmente escindida" 24 .

La independencia de la patria no implicó la libertad jurídica del país, pues el Derecho Castellano de facto siguió vigente luego de 1821, aunque varios años después se reformó propiamente la legislación penal nacional, por motivos técnicos legales y políticos criminales. El comienzo de la independencia del Perú se manifestó por los acontecimientos legales siguientes:

- Reglamento provisional de marzo de 1821, verifica que “inicialmente el General José de San Martin reconoció la validez de todas las disposiciones españolas que no contravengan el principio de libertad o independencia y que su derogación no fuese por autoridad competente"25

- Decreto de octubre de 1821, establecía la pena capital para el funcionario de hacienda que incumpliere con su obligación maliciosa.

- Decreto de enero de 1822, determinó que se modifique la sanción penal de la normatividad anterior por fusilamiento.

- Constitución de 1823, conservó la pena capital y consideró abrogar las sanciones infames y aquellas que amplíen sus secuelas a la descendencia del delincuente.

Por su parte, Bolívar dio un Decreto en marzo de 1824, disponiendo pena capital para los empleados que cometan delito de contrabando, propulsando el ámbito penal económico. Asimismo, "admitió a composición las tierras del Estado que se encontraban en posesión precaria con el propósito de conseguir rentas para el ejército. Esto implicó la disolución de la comunidad indígena ${ }^{26}$, incompatible con las ideas liberales de aquel entonces, pero esta norma no fue acatada, pues los indígenas se resistieron en agosto de 1827 contra las autoridades estatales, obligándoles a suspender toda venta" 27.

La Batalla de Ayacucho, que significó la culminación del dominio español ${ }^{28}$, en América del Sur, se llevó a cabo en Pampa de Quina, el 09 de diciembre de 1824. Después de la derrota de los realistas, se dio la Capitulación de Ayacucho, que fue firmada por José Canterac y Antonio José de Sucre. Siendo derrotado La Serna, en la Batalla de Ayacucho, el general español Pedro Antonio Olañeta, resistió con

24. Javier Villa Stein, op. cit., pp. 80 - 81.

25. Raúl Peña Cabrera, Tratado de derecho Penal. Estudio programático de la parte General, (Lima, Grijley, 1999), p.154. 26. En el mismo sentido, Eduardo Galeano, Las venas abiertas de América Latina, Setenta y cinco ediciones. (Buenos Aires: Siglo Veintiuno Editores, 2003), p. 187.

27. Javier Ysrel Momethiano Santiago, op. cit., p. 312.

28. Sin embargo, la soberanía que tenía el Imperio español sobre los territorios americanos no fue renunciado formalmente hasta 1879 . 
sus tropas en el Alto Perú contra el ejército independiente, y siendo gravemente herido el 01 de abril de 1825, en la campaña militar de Tumusla, falleció al día siguiente. Posteriormente, José Ramón Rodil y Campillo, negó la Capitulación de Ayacucho y como comandante militar de la Fortaleza del Real Felipe y de los Castillos del Puerto del Callao, resistió hasta el 22 de enero de 1826 y aceptó capitular ante Bartolomé Salom general venezolano.

\section{LA LEGISLACIÓN PENAL REPUBLICANA EN EL SIGLO XIX}

La independencia y la República del siglo xix no eliminaron el problema existente entre el grupo dominante y el grupo explotado, el primero era hispano-criollo (estilo de vida), y el segundo era mestizo-indígena (costumbres). Este periodo, fue marcado por los sucesos jurídicos penales siguientes:

- Proyecto de Código Penal de 1828. En marzo de 1828 dispusieron repartirles las tierras a los indígenas con licencia, pero exigiéndoles previamente como requisito que sepan leer y escribir, esta norma tampoco tuvo éxito, defen-diéndose de esta manera a los hacendados criollos; sin embargo, varios indios empezaron a vender sus tierras sin título, lo que originó posteriormente problemas judiciales. Por eso, los criollos desconfiaban de los campesinos, ya que no olvidaban la sublevación de Túpac Amaru y los Angulo, que más que dirigirse contra la monarquía era una insurrección contra la centralización y racionalización de la administración del orden estamental. En este mismo periodo anual, Bolívar designó como presidente a Manuel Lorenzo de Vidaure -quien fue Oidor de la Audiencia del Cusco en 1811-sabiendo de su tarea pre legislativa. De esta manera, bajo la influencia del pensamiento penal inglés y francés, se dió origen al primer Proyecto de Código Penal -Código Criminal- Sudamericano de Manuel Lorenzo de Vidaure de 1928, que concebía al delito como una voluntad del hombre que ocasiona un mal con discernimiento, y su punibilidad tiene por finalidad el desquite del crimen producido y su futura evitación puesto que la tradición española había continuado vigente, ya que la redacción de este proyecto de Código Penal se inspiraba en el Código Penal español de 1820 y el Código Penal francés de 1810. Además, en las ideas de César Beccaria, Rousseau, Filangeri, Montesquieu, Grocio, Locke y Betham. Las sanciones penales que se establecían eran: la infamia, trabajos públicos, expatriación, multa, confiscación, etc. Este Proyecto de 1928 se publicó en Cuba, pero siendo acusado de conspiración Vidaure llegó a Estados Unidos publicando totalmente su Proyecto en Boston.

- Código Penal de Santa Cruz de 1836 - 1838. Esta normatividad penal surgió a raíz de la Confederación Perú-Boliviana, bajo el Protector Supremo Andrés de Santa Cruz, y estuvo vigente en el Estado Sur, el 13 de octubre de 1836 hasta que esta se derogó en 1838 por Agustín Gamarra, restableciéndose de esta forma la normatividad preexistente de origen hispano, y que según Basadre "nos informa que los cuerpos legales fueron suprimidos con la restauración y calificados de ultraje y humillación al Perú por patriotas intransigentes y abogados y magistrados conservadores" ${ }^{29}$. Este estatuto penal de 1836 , que tuvo como

29. Jorge Basadre, mencionado por Fernando De Trazegnies Granda. La idea de derecho en el Perú republicano del siglo XIX, (Lima: Editorial Universitaria, 1967), pp. 160-161. 
base al Código Penal español de 1822, y de influencia francesa, derivada del enciclopedismo y del movimiento codificador francés, definía al delito como un comportamiento libre, voluntario y malicioso ${ }^{30}$.

- Código Penal peruano de 1863. En el primer gobierno de Ramón Castilla se inicia el proceso legislativo nombrando el Congreso varias comisiones. La Primera Comisión de 1853 -integrada por Pablo Cárdenas, Santiago Távara, Carlos Pacheco, Ignacio Novoa, y otros- que elaboró el Proyecto de Código Penal, se sometió a una Segunda Comisión de 1856 -presidida por José Simeón Tejada- encargada de revisar el Proyecto presentado, y la Tercera Comisión de 1861 -integrada por José Silva Santisteban, Juan de la C. Lizárraga, Evaristo Gómez Sánchez, José María Pérez y otros- estableció la segunda revisión del mismo y su aprobación. Este primer cuerpo jurídico patrio ${ }^{31}$ se estructuró en el Libro primero: Parte general, Libro segundo: Los delitos y penas, y Libro tercero: Las faltas; inspirándose en el Código Penal español de 1848 y su reforma de 1850, así como en el Código Penal francés de 1810, napolitano de 1819, y brasileño de 1830. Esto significó que "el legislador peruano no realizó una servil imitación, sino que modificó el "Código importado" para adecuarlo, de acuerdo con su concepción político-social, al estado del país. Con este objeto, simplificó o suprimió diversas disposiciones" ${ }^{2}$. En sus disposiciones se destacan: La ley penal (comprendiendo la garantía nullum crimen nulla poena sine lege y principio nulla poena sine inditio); el delito (entendiéndose como la acción u omisión maliciosa y voluntaria. Además, abarcaba a la tentativa, a las circunstancias eximentes de responsabilidad, atenuantes, agravantes y grados de participación en el delito); y la pena (determina la escala de sanciones principales, empezando por la pena de muerte, penitencieria, cárcel, reclusión, arresto, expatriación, confinamiento, inhabilitación, destitución de empleo o cargo y su suspensión, multa, represión y caución. Además, estableciéndose las sanciones accesorias de interdicción civil, inhabilitación, perdida de los instrumentos con que realizó el delito, pago por los dańos y costos procesales, vigilancia de la autoridad, y reparación civil) ${ }^{33}$. Los que conocieron en profundidad este Código, fueron Ricardo Heredia (siguiendo a Francisco Pacheco que defendió las ideas de castigo ${ }^{34}$, siendo el fin intimidar moderadamente a la sociedad en aras de mantener el orden social) $)^{35}$ y José Silva ${ }^{36}$ (siguió la doctrina de Derecho Penal natural ${ }^{37}$ creada por Krause y divulgada por Ahrens y Roder), quien

30. Vid. Javier Ysrel Momethiano Santiago, op. cit., p. 314.

31. Siendo, el Código Penal argentino de 1887 y el Código Penal chileno de 1875.

32. José Hurtado Pozo, La ley importada. Recepción del derecho penal en el Perú, (Lima, Talleres de industrial grafica S. A. , 1979), p. 44.

33. Luis Alberto Bramont Arias, Derecho Penal. Parte general. Tomo I, (Lima: Talleres Litográficos de Villock S.A., 1972), pp. 112 - 113.

34. En tal sentido, no eran conocidas las instituciones de prevención y medidas de seguridad.

35. El Doctrinarismo francés -implicaba una síntesis entre libertad y orden que los españoles liberales defendían- vinculado al Eclecticismo penal propugnado por Rossi se manifestó a mediados del siglo XIX en España.

36. Propulsó que se adecue el Derecho Público al modelo republicano peruano, sustentándose en las ideas racionalistas.

37. Posteriormente, se produce un rechazo a estas ideas por, Manuel Vicente Villarán, Oscar Miroquesada, Juan Bautista Lavalle y Javier Prado Ugarteche, impulsando la corriente positivista, Vid. Luis Jiménez de Asúa, Derecho penal en la República del Perú, (Lima: Ediciones jurídicas, 1987), pp. 22-23. Mientras en Europa se fomenta la lucha de la escuela 
enseño Derecho Penal en el Primer Colegio Nacional de la Republica de Nuestra Señora de Guadalupe, y reemplazándolo a Pedro Gálvez. El Colegio Nacional de Nuestra Seńora de Guadalupe, fundado en 1840 por los liberales Domingo Elías y Nicolás Rodrigo se encargaron de la educación primaria, luego de la secundaria y superior -destacando del plan de estudios los cursos de Historia del Perú, Introducción a la Cátedra de Economía Política y la enseñanza por el Derecho-, incluyendo el ius naturalismo y el contrato político a partir de 1850, durante el rectorado de Pedro Gálvez. A diferencia del Convictorio de San Carlos, creado en 1770 y propulsado por el rectorado conservador de Bartolomé Herrera a partir de 1842, volvió a resplandecer como lo era bajo la dirección de Toribio Rodríguez de Mendoza, considerando proscribir las ideas modernas de la ilustración, reemplazándolas por aleccionamientos religiosos y políticos ortodoxos. "Recordemos que en el caso de los estudios ius naturalistas y de derecho internacional, Rodríguez de Mendoza había empleado el texto de Heinecio Elementa iuris naturae et Gentium (Elementos de derecho natural y de gentes o internacional, 1737), porque este autor mediaba entre el ius naturalismo y racionalismo moderno de su maestro Punfendorf y la doctrina de los Teólogos de la Segunda Escolástica de que el poder proviene de Dios y que este lo entrega al pueblo, el cual lo traslada al gobernante mediante un compromiso o pacto" 38 Ambos Colegios contribuyeron a la formación política y jurídica superior, debido a la labor limitada de la docencia en la Universidad Nacional Mayor de San Marcos, que tenía bajo su tutela al Real Colegio de San Carlos.

\section{LA DENOMINADA “SEGUNDA INDEPENDENCIA DEL PERÚ”}

La población que apoyo con joyas, dinero y bienes, voluntariamente u obligatoriamente, ya sea a los generales realistas o patriotas, colocaban sus firmas en promesas de colaboración, que debían ser honradas con la victoria. Habiendo ganado los patriotas, reconocieron su deuda con Espańa. Estos acreedores formaron la Sociedad General de Crédito Mobiliario Español, que reunió títulos de deudores peruanos, pues consideraban que se debía aprovechar la exportación del guano, y exigir al Estado del Perú cumpla con el pago. Una muerte de un trabajador español en la hacienda Tambo, fue la excusa para que la escuadra española tomara las islas de chincha, principal yacimiento de guano en 1864. En Arequipa, se desata la revolución del Coronel Mariano I. Prado, quien derrocó al gobierno de Pezet, formando la Cuádruple Alianza con Bolivia, Ecuador, y Chile, con la finalidad de declarar la guerra a España.

Entonces, el combate del 02 de mayo de 1866 -siendo héroe nacional José Gálvez, militares y civiles en defensa del Callao- mas que significar una "Segunda independencia del Perú, y de Sudamérica"; parece implicar que Espańa actuó por intereses económicos y políticos. Posteriormente, se dio el suceso jurídico penal siguiente:

penal clásica y positivista.

38. David Sobrevilla, La filosofía del derecho en el Perú, (Lima: Fondo Editorial de la Pontificia Universidad Católica del Perú, 2013), pp. 77 - 78. 
- Proyecto de Código Penal de 1874. Las propuestas legislativas de reforma penal encargadas a las comisiones de 1871, 1873 y $1877^{39}$ fueron sustentadas desde la óptica de la escuela positivista e impulsada mediante el Proyecto de 1874 por Juan Antonio Ribeyro, "con el objeto de modificar el Código Penal de [1863]; [pero] no ofrecieron variaciones relevantes, ya que carecieron de sustento jurisprudencial; y solo reiteraron las ideas de libertad, culpabilidad y de retribución punitiva, que fueron utilizadas maliciosamente por la República oligárquica” ${ }^{30}$.

\section{LA GUERRA DEL PACÍFICO}

La declaración de guerra de Chile a Bolivia y Perú, fue el 05 de abril de 1879. En los meses siguientes, Chile logró conquistar los desiertos de la costa, por su supremacía naval. El 14 de agosto de 1879, se firma el Tratado de Paris, entre el reino de España y la república del Perú, acordando la paz y amistad; además reconociendo España la independencia del Perú, como secuela de la Guerra hispano sudamericana. Antes de finalizar 1879, Chile ocupó Tarapacáa ${ }^{41}$, y a comienzos de 1880 , se apoderó de Tacna y Arica $^{42}$, lo que determinó que Bolivia nos abandonará en la guerra. Luego Chile ingresó a Chorrillos y Miraflores en 1881. A pesar que en Miraflores se implementaron diez reductos, encontrándose en el segundo reducto, el Batallón $\mathrm{N}^{\circ} 4$ al mando del abogado Ramón Ribeyro, juntamente con magistrados, diputados y abogados. El ejército chileno ocupó Lima, el 17 de enero de 1881. Sin embargo, Andrés Avelino Cáceres Dorregaray y Leoncio Prado Gutiérrez, resistieron al enemigo. La guerra entre Perú y Chile, continuó hasta la firma del tratado de Ancón de 1883. Posteriormente, se apreció el acontecimiento jurídico penal siguiente:

- Ley contra el delito de contrabando de 1896. Normatividad que enfatizó el campo penal económico al sancionar el comportamiento prohibido, con pena corporal aflictiva, multa, etc.

\section{LA REFORMA LEGISLATIVA PENAL EN EL SIGLO XX}

Desde 1890 hasta 1900 se aprecio una fuerte demanda por el caucho, lo que ocasionó que varios sujetos desaparezcan a indígenas de Loreto y Madre de Dios. A comienzos del siglo XX, se dio inicio a un nuevo esfuerzo en materia penal, acentuándose por los sucesos jurídicos siguientes:

39. Decreto Supremo de fecha 03 de Julio de 1877, emitido por Mariano Ignacio Prado para reformar la legislación sustantiva y adjetiva.

40. Javier Ysrel Momethiano Santiago, op. cit., p. 315.

41. Luego de la victoria del ejército peruano en Tarapacá el 27 de noviembre de 1879, se dirigieron con la población a Arica por venganza de los chilenos.

42. Francisco Bolognesi Cervantes y Alfonso Ugarte y Vernal, que murieron el 07 de junio de 1880, defendieron la Plaza de Arica, con el ejército peruano. Mientras, Miguel Grau Seminario, que murió el 08 de octubre de 1879 en el Combate de Angamos, colocó en aprietos a la escuadra chilena por varios meses. 
- Proyecto de Código Penal de 1900 -1902. La elaboración del referido cuerpo normativo delegado a diversas comisiones no fue divulgado oficialmente. Estas comisiones integradas por magistrados siguieron la legislación hispánica, considerada un sistema tradicional.

- Código Penal de 1924. Este segundo texto legal nacional se publicó el 10 de enero de 1924, y entró en vigor el 24 de julio del mismo año, durante el segundo gobierno de Augusto B. Leguía, y que luego se prolongó por varios años, conociéndosele como Oncenio. Su normatividad fue propulsada desde 1916 por Víctor M. Maúrtua, y se inspiró en el Proyecto suizo de 1915, 1916, y 1918; así como en el Código Penal italiano de 1889, el Código Penal uruguayo de 1889, el Proyecto sueco de 1918, y el Código Penal argentino de 1921. Pero, Maúrtua no era especialista en Derecho Penal, sino en Derecho Internacional, pues como diplomático conocía idiomas foráneos permitiéndole apreciar los Proyectos de Código Penal avanzados para ese entonces, y redactar el Código Penal de 1924. Para elaborar Maúrtua su Código, tuvo presente la legislación y doctrina extranjera, vinculándolo con nuestra realidad. Sin embargo, "los magistrados siguieron empleando, en la aplicación de las nuevas disposiciones sus esquemas mentales caducos y los juristas, con raras excepciones, no han asimilado correctamente las concepciones jurídicas que se hallan

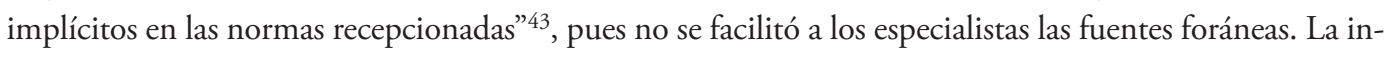
fluencia positivista ${ }^{44}$ y causalista ${ }^{45} 46$ es el fundamento epistemológico del Código Penal de Maúrtua, en tal sentido el delito era una conducta típica, antijurídica, imputable, culpable y punible, pues la finalidad de la sanción penal no es el hecho punible, sino el agente. Además, al juzgador se le otorgó amplia libertad para imponer la sanción penal, pues no existía en el texto sustantivo escalas en la determinación legal de la pena; pues se apreciaba todas las circunstancias, es decir, las personales y objetivas que le servirán para medir su culpabilidad y peligrosidad. Este texto normativo estableció en el Libro primero: Disposiciones generales; en el Libro segundo: Delitos de la Parte especial; en el Libro tercero: Las faltas; y en el Libro cuarto: La vigencia y aplicación de la norma sustantiva. En sus disposiciones se distinguen: La ley penal (comprendiendo la garantía de la integridad moral y física del reo; así como la máxima nulla poena sine iuditio, nullum crimen nulla poena sine lege, y la aplicación de la ley penal en el tiempo y espacio); el delito (abarcando a la culpabilidad y a las causas que excluyen o atenúan la represión del delito); y la sanción penal (establece las penas siguientes: internamiento, penitencieria, relegación, prisión, expatriación, multa e inhabilitación; y las medidas de seguridad siguientes: responsabilidad limitada -indígena degenerado por el alcohol o sujeción- o que el delito sea causa de la ociosidad o su vida ${ }^{47}$. Este cuerpo legal concreta el modelo político criminal, tratamiento especial para menores, aumento de atenuantes, incorporación

43. José Hurtado Pozo, Manual de Derecho Penal. Parte general I, (Lima: Grijley, 2005), pp.114 -115.

44. También, el Proyecto del Código Indígena se fundamentó en el estado peligroso, imputando al sujeto activo medidas de corrección. Esta propuesta fue defendida por la escuela positivista. Al respecto, Vid. Felipe Andrés Villavicencio Terreros, Diversidad Cultural y Derecho Penal, (Lima: Ideas solución editorial, 2017), pp. 169 - 171.l.

45. Julio D. Espino Pérez. Código Penal, (Lima: Editorial importadora Sevillana, Sexta edición, 1982), p.19.

46. Posteriormente y en la medida de lo posible, con nuevo rumbo dogmático finalista. Vid. José Antonio Silva Vallejo. Filosofía del Derecho, (Lima: Ediciones legales, segunda edición, 2012), p. 78.

47. Luis Alberto Bramont Arias. Op. cit., p. 116. 
del concepto de reincidencia y de las condiciones de culpabilidad, creación de colonias penales para habituales, y relegación para peligrosos en comunidades agrícolas, y penitencieria, prisión, multa, inhabilitación, delito frustrado y prescripción siguiendo el prototipo italiano ${ }^{48}$. También, en el numeral 5 del artículo 246 y el artículo 248 del Código Penal de 1924, incursionaba en la represión penal económica, pero en forma poco precisa respecto a la defraudación, en actos de perjuicio a la administración pública, y su administración desleal. Sin embargo, el Código de Maurtua se complementa con la Ley Represora de contrabando, en junio de 1966.

- Proyecto de Código Penal de 1928. Esta propuesta normativa elaborada por Ángel Gustavo Cornejo y Plácido Jiménez da inicio a la reforma del Código Penal de 1924. Este texto legal se dividió en: Primera parte (Delincuencia: principios generales, delitos en específico, faltas y contravenciones) y Segunda parte (prevención vinculada a las medidas de seguridad). En sus disposiciones resalta: La ley penal (estableció que su finalidad es la defensa del orden social, y preceptúa el principio nulla poena sine iuditio), el delito (comprende a los comunes: Delitos políticos y sociales; así como a los especiales: Las infracciones previstas en leyes penales privativas, tratados o acuerdos con demás Estados); el delincuente (determinándose su peligrosidad delictual y predelictual, así como su atenuación o agravación), y la sanción penal (estableciéndose las penas de presidio, penitencieria, cárcel, arresto, expatriación, inhabilitación, y multa; así como las medidas de seguridad de relegación, internamiento en asilo, manicomio, reformatorio, casa de trabajo o tratamiento, confinamiento, trabajo disciplinario, caución, y expulsión. Además determinándose las medidas preventivas de expulsión de territorio, secuestro o vigilancia policial, reglas de conducción y (correccional $)^{49}$.

- Decreto Supremo No 136 de 1965. Bajo la Presidencia de la República de Fernando Belaunde Terry, se nombró una Comisión Revisora del Código Penal de 1924. Esta Comisión estuvo integrada por Manuel G. Abastos, Luis Alberto Bramont Arias, Luis Eduardo Roy Freyre, Raúl Peña Cabrera, Octavio Torres Malpica, y otros.

- Ley contra la adulteración, acaparamiento y especulación de 1976. Durante el gobierno militar de Juan Francisco Velasco Alvarado, se estableció castigar la reincidencia de la delincuencia económica, lo que determinó la vulneración del principio ne bis in ídem.

- Proyecto del Código Penal de 1981. En el segundo gobierno de Fernando Belaunde Terry, se emitió la Resolución Suprema N N $^{\circ} 70-81-J U S$ de fecha 08 de setiembre de 1981, que formó una Comisión integrada por Luis Eduardo Roy Freyre, Víctor Maúrtua Vásquez, Eduardo Mimbela de los Santos, y otros, con la finalidad de elaborar el proyecto normativo penal sustantivo.

48. Raúl Peña Cabrera. Op cit., pp. 160 - 161.

49. Luis Alberto Bramont Arias. op. cit., p. 118. 
- Ley sobre delitos económicos de 1981. Se pretendió perfeccionar los ilícitos de acaparamiento, adulteración de productos y alteración de precios.

- Proyecto del Código Penal de 1984. Por Ley No 23859 de fecha 05 de julio de 1984, se otorga facultades al Poder Ejecutivo de legislar en materia penal sustantiva, en tal sentido se nombró una Comisión Revisora conformada por Luis Alberto Bramont Arias, Juan Portocarrero Hidalgo, Javier Alva Orlandini, y otros.

- Proyecto del Código Penal de 1985. Estando en la Presidencia de la República Alan Gabriel Ludwing García Pérez, se consideró el proyecto anterior y realizando sus enmiendas respectivas, se presentó nuevamente.

- Proyecto de Código Penal de 1986. La Resolución Ministerial Nº 193-85-JUS permitió que los juristas: Luis Alberto Bramont Arias, Juan Portocarrero Hidalgo, Edmundo Haya de la Torre, y otros colaborarán en la Comisión Consultiva del Ministerio de justicia, para propulsar la elaboración de un nuevo cuerpo legal.

- Proyecto del Código Penal de 1989. Por Ley N²3859 y 24901 se formó una comisión revisora que analizó el Proyecto del Código Penal de 1986 y presentó su propuesta de la Parte general. Esta comisión fue integrada por Felipe Osterling Parodi, Pedro Méndez Jurado, Luis Alberto Bramont Arias, Luis Eduardo Roy Freyre, y otros.

- Proyecto del Código Penal de 1990. Considerando la normatividad antes referida, se analizó y presentó por la comisión encargada, la Parte general y Parte especial del texto legal.

- Código Penal de 1991. Bajo el gobierno de Alberto Kenya Fujimori Fujimori - que luego propició el autogolpe de Estado de 1992- se expidió el Decreto Legislativo $\mathrm{N}^{\circ}$ 635, que estableció el Libro Primero: Parte general, el Libro segundo: Parte especial, y el Libro tercero: De las faltas. Este Código hace suyo los planteamientos del funcionalismo moderado ${ }^{50}$. En sus disposiciones destaca lo siguiente: La ley penal (abarcando el principio de legalidad, lesividad, proporcionalidad, jurisdiccionalidad, etc.; así como la aplicación de la ley penal en el tiempo, espacio y persona); el hecho punible (comprendiendo la autoría y participación, la tentativa, y las causas que eximen o atenúen la responsabilidad); y la sanción penal (estableciéndose las penas siguientes: privativa de libertad -determinada, indeterminada y vigilancia electrónica personal-, limitativas de derechos -prestación de servicios a la comunidad, limitación de días libres e inhabilitación-, y multa; así como las medidas de seguridad siguientes: internamiento y tratamiento ambulatorio. Además, incluye la reparación civil y las consecuencias accesorias). Este cuerpo legal vigente pretende concretar la moderna política criminal, considerando al Derecho Penal como una garantía para el Estado Social y Democrático de Derecho. Esta Ley Penal reforma el criterio de ubicuidad,

50. Luis Alberto Bramont Arias, y Luis Alberto Bramont - Arias Torres. Código Penal Anotado, (Lima: Editorial San Marcos, 1995), pp. 38 - 39. 
omisión impropia, error de tipo, error de prohibición, error de prohibición culturalmente condicionado, entre otros temas relativos a la realización de lo ilícito. Asimismo, se incorporan las penas restrictivas de la libertad -últimamente abroga a la expatriación-, y las limitativas de derechos. Se unifica la pena privativa de libertad y se modifica la pena de multa. También se proscribe a la reincidencia y habitualidad, aunque actualmente se la considera como una circunstancia agravante, con lo que discrepamos. La evolución de la criminalidad económica permite que este cuerpo legal incluya los delitos de abuso de poder económico, publicidad engañosa, concentración crediticia, pánico financiero, y los delitos monetarios, aunque estas conductas se han reducido a infracciones administrativas, en virtud a la Ley de represión de conductas anticompetitivas y a la Ley de represión contra la competencia desleal, esto como secuela del Acuerdo de Promoción Comercial entre Estados Unidos de América y nuestro país. A pesar de esto, se han incorporado a la legislación penal peruana las conductas prohibidas de abuso de información privilegiada, delitos informáticos, conducción ilegal de casinos, etc.

- Ley N²5475 de 1992. Se reguló como ley penal especial el delito de terrorismo.

- Decreto Legislativo Nº 813 de 1996. Se reguló los delitos tributarios en la ley penal especial.

- Ley contra delitos agravados de 1998. Esta normatividad dada durante el segundo gobierno de Alberto Kenya Fujimori Fujimori, y que luego fue derogada, modificó los delitos de homicidio calificado, secuestro, robo simple, robo agravado, violación de menores de edad, y extorsión, contenidos en el Código Penal de 1991, ocasionando imprecisiones en ciertos comportamientos prohibidos incrementados, al igual que su punibilidad.

\section{LOS IMPULSOS PARA MEJORAR LA LEGISLACIÓN PENAL NACIONAL EN EL SIGLO XXI}

A comienzos del presente siglo, se dió un nuevo esfuerzo en materia penal, que fue marcado por los sucesos jurídicos siguientes:

- Ley No 27378 de 2000. Estando en la Presidencia de la República Valentín Demetrio Paniagua Corazao, se expidió la referida ley que estableció beneficios por colaboración eficaz en el ámbito de la criminalidad organizada, ya que se difundió en Canal N, el 14 de setiembre de 2000, un video donde se apreció a Vladimiro Montesinos entregando dinero al después congresista Alexander Kouri; y más adelante se reveló cuentas millonarias secretas en el exterior del ex asesor presidencial, que dio origen al descubrimiento de un aparato de poder organizado. En este contexto, se expidió la normatividad mencionada, pero sin indicar que es criminalidad organizada.

- Comisión de la Verdad y Reconciliación de 2001. Bajo el periodo de transición democrática, se convocó a dicha comisión, encargada de analizar las causas de la violencia terrorista desde 1980 hasta el 2000. En la investigación se realizó varias audiencias y se recabó miles de testimonios. El informe final fue publicado en el 2003. 
- Ley N. 27837 de 2002. Bajo el gobierno de Alejandro Celestino Toledo Manrique, el 03 de octubre de 2002, se crea una Primera Comisión Especial encargada de revisar el Código Penal de 1991, que tuvo como tarea sistematizar la normatividad penal.

- Ley $N^{\circ} 28008$ de 2003. Se reguló como ley penal especial los delitos aduaneros.

- Ley N 27936 de 2003. Esta normatividad estableció las condiciones de ejercicio de la legítima defensa.

- Ley N. 28891 de 2006. En el segundo gobierno de Alan Gabriel Ludwing García Pérez, el 13 de octubre de 2006, se crea una Segunda Comisión Especial Revisora del Código Penal de 1991, que retomó su labor aprobando el Título Preliminar y el artículo $1^{\circ}$ al $27^{\circ}$ de la Parte General de la Ley Penal.

- Ley N. 29153 de 2007. El 16 de diciembre de 2007, una Tercera Comisión Especial Revisora del Código Penal de 1991, encargada de crear una nueva Comisión Especial Revisora del Código Penal a falta de culminación del Anteproyecto de Reforma de la Ley Penal. Esta Comisión se instaló el 26 de marzo de 2008, debido a que el Congreso de la República no sesionó hasta ese mes.

- Proyecto de Ley N. ${ }^{\circ}$ 2855/2008-CR El Pleno del Congreso de la República aprueba la prórroga del plazo de vigencia de la Comisión por un ańo adicional, publicado en el Diario Oficial El Peruano, el 13 de diciembre de 2008 por Ley N. 29295.

- Proyecto de Ley N. 3616/2009-CR. Apreciando los avances técnicos serios de la Comisión, el Pleno del Congreso de la República, aprueba ampliando su plazo de vigencia hasta diciembre de 2010, publicado en el Diario Oficial El Peruano, el 18 de noviembre de 2009. Durante el 2010 y luego de aprobar el Congreso de la República el plazo ampliatorio de vigencia de la Comisión, se tuvo como objetivo terminar el trabajo de revisión, pues se tenía un relevante avance de la Parte Espe $\neg$ cial del Código Penal, propulsándose asimismo varias reuniones de trabajo para hacer viable el proceso de reforma.

- Anteproyecto del Código Penal de 2008 - 2010. Con la finalidad de dar a conocer las modificatorias realizadas y la adecuación de los ilícitos previstos en el Estatuto de Roma de la Corte Penal Internacional $\mathrm{u}$ otras normas supranacionales, que respondieron a los avances de la legislación y jurisprudencia sobre la materia ${ }^{51}$. Este anteproyecto, consideró en el Libro primero: Parte general, en el Libro segundo: Parte especial, en el Libro tercero: Delitos contra el Derecho Internacional de los Derechos Humanos y el Derecho Internacional Humanitario, y en el Libro cuarto: Faltas. En sus disposiciones se distinguen: La ley penal (comprendiendo el principio de legalidad, lesividad, proporcionalidad, analogía in bonam partem, ne bis in idem, etc.; así como la aplicación de la ley penal en el espacio, tiempo y persona); el hecho

51 Javier Ysrael Momethiano Santiago. Manual de Derecho Penal. Parte general, (Lima: Editorial San Marcos, Segunda edición, 2016), p. 63. 
punible $^{52}$ (estableciéndose la autoría y participación, la tentativa y las causas que eximen o atenúan la responsabilidad penal); y la sanción penal (abarcando las penas siguientes: privativa de libertad-temporal e indeterminada-, limitativas de derechos - prestación de servicios a la comunidad, limitación de días libres e inhabilitación-, y multa; así como las medidas de seguridad siguientes: internamiento, tratamiento ambulatorio, y restricción de derechos o facultades. Además, incluye la reparación civil, el decomiso, y las medidas aplicables a las personas jurídicas).

- Decreto Legislativo № 1106 de 2012. Siendo Presidente de la Republica Ollanta Moisés Humala Tasso, se prevé en el artículo 1, 2, 3, 4, 5, y 6 supuestos de hecho referidos a la lucha contra el lavado de activos y otros delitos relacionados a la minería ilegal y crimen organizado.

- Proyecto de Ley No 3491/2013-CR. Esta propuesta normativa trata sobre la diversidad cultural, y la justicia indígena, la interpretación cultural, el ne bis in ídem y el error de comprensión culturalmente condicionado.

- Ley No 30077 de 2013. Se regula el crimen organizado como ley penal especial.

- Ley No 30096 de 2013. Se regula como ley penal especial a los delitos informáticos.

- Dictamen de la Comisión de Justicia y Derechos Humanos del Congreso de la República de 2015. Esta referido a la diversidad cultural e interpretación intercultural, a la comprensión culturalmente condicionada y a la jurisdicción especial.

- Decreto Legislativo $N^{\circ} 1182$ de 2015. Se regula el uso de datos derivados de las telecomunicaciones para la identificación, localización y geolocalización de equipos de comunicación, en la lucha contra la delincuencia y el crimen organizado, lo que modifica el artículo 162, 222-A, y 368-A del Código Penal e incorpora el artículo 162-A del Código Penal.

- Decreto Legislativo $N^{\circ} 1237$ de 2015. Normatividad que modifica el Código Penal, aprobado por el Decreto Legislativo $\mathrm{N}^{\circ} 635$, que modifica varios dispositivos de la parte general y especial.

- Dictamen de la Comisión de Justicia y Derechos Humanos de 2016. El texto sustitutorio trata sobre la diversidad cultural e interpretación intercultural, el error de comprensión culturalmente condicionado y la jurisdicción especial.

- Decreto Legislativo N 1243 de 2016, Durante el gobierno de Pedro Pablo Kuczynski Godard, se modificó varios artículos del Código Penal para ampliar el plazo de duración de la pena de inhabilitación; asimismo se incorporó la pena de inhabilitación perpetua para los delitos cometidos contra la administración pública, y se dispuso crear un registro único de condenados inhabilitados.

52 Son infracciones punibles los delitos y faltas que están preceptuados en el artículo 11 del Anteproyecto de la Ley de Reforma del Código Penal. Sin embargo, los crímenes son incluidos por el Libro tercero de la misma propuesta legislativa. 
- Proyecto de Ley N 498/2016-CR. Se refiere al error de comprensión culturalmente condicionado.

- Decreto Legislativo $N^{\circ} 1244$ de 2016. Esta normatividad fortalece la lucha contra el crimen organizado y la tenencia ilegal de armas.

- Decreto Legislativo 1245 de 2016. Esta normatividad modifica el texto penal para garantizar la seguridad de la infraestructura de hidrocarburos.

- Decreto Legislativo No 1300 de 2016. Se regula el procedimiento especial de conversión de penas privativas de la libertad por penas alternativas en ejecución de condena.

- Decreto Legislativo $N^{\circ} 1322$ de 2017. Se regula la vigilancia electrónica personal.

- Decreto Legislativo $N^{\circ} 1323$ de 2017. Esta normatividad fortalece la lucha contra el feminicidio, la violencia familiar y la violencia de género.

- Decreto Legislativo $N^{\circ} 1348$ de 2017. Se refiere al Código de responsabilidad penal de adolescentes.

- Decreto Legislativo No 1351 de 2017. Esta normatividad modifica el Código Penal a fin de fortalecer la seguridad ciudadana.

- Decreto Legislativo $\mathrm{N}^{\circ} 1352$ de 2017. Esta norma amplia la responsabilidad administrativa de las personas jurídicas, y se aprecia la figura del compliance criminal.

- Informe Nº 01 - 2017 - JUS/CNPC. Propuesta revisada y validada por el grupo de trabajo conformado por integrantes del Consejo Nacional de Política Criminal.

- Comisión de reforma del Poder Judicial de 2018. Bajo la Presidencia de la República de Martin Alberto Vizcarra Cornejo, se conoció el escándalo de los audios de conversaciones de jueces y miembros del Consejo Nacional de la Magistratura, como secuela de esto, se anunció la creación de dicha comisión.

- Decreto Legislativo $N^{\circ} 1373$ de 2018. Esta normatividad regula la extinción de dominio.

- Decreto Legislativo $\mathrm{N}^{\circ} 1410$ de 2018. Se incorporó el delito de acoso sexual, chantaje sexual y difusión de imágenes materiales audiovisuales o audios con contenido sexual al Código Penal.

- Ley de Protección Policial de 2019. Esta normatividad modifica innecesariamente el numeral 11, articulo 20 del Código Penal, debiendo interpretarse en favor del efectivo policial, prohibiendo que el juez penal dicte detención preliminar y prisión preventiva; y en su caso sólo comparecencia, lo que vulnera principio de independencia judicial.

- Decreto Legislativo $N^{\circ} 1459$ de 2020. Esta normatividad regula el procedimiento especial de conversión de penas privativas de libertad por penas alternativas, en ejecución de condena, para que los condenados por delito de omisión de asistencia familiar accedan a este beneficio, bajo ciertos presupuestos, lo que se adecúa al estado de emergencia sanitaria que afronta el Perú por el Covid-19. 
- Decreto de Urgencia No 026 de 2020, Se estableció diversas medidas excepcionales y temporales para prevenir la propagación del covid - 19. Es relevante apreciar que no hubo modificatorias en algunos supuestos de hecho previstos en los delitos contra la salud pública, pues estos, no siguieron en su análisis la interpretación progresiva, ya que los tipos penales previstos surgieron para luchar contra el contagio venéreo, y luego sin modificar los dispositivos referidos, forzaron su adecuación al contagio por VIH/SIDA, generando serios problemas de interpretación, al igual que al contagio por COVID -19.

- Ley N 31146 de 2021, Estando en el gobierno Francisco Rafael Sagasti Hochhausler, se sistematizó varios artículos del Código Penal, referidos a trata de personas y explotación sexual para denominarlos en adelante delitos contra la dignidad humana.

\section{CONCLUSIONES}

- En la época preínca no se conoció la escritura, puesto que no hubo testimonios de oídas sobre la existencia del ámbito de punibilidad que los cronistas pudieran haber recogido.

- En el Imperio del Tahuantinsuyo el creador del derecho era el Inca, pues su ley lo hacía conocer al pueblo por intermedio de los quipucamayoc y amautas; utilizando los refranes al carecer de escritura, y su represión penal se extendía al orden económico del incanato, aunque con trato diferenciado para los habitantes pues se exigía el endurecimiento de las sanciones, en la idea de primera velocidad del derecho penal.

- Lo esencial de aplicar un derecho penal foráneo es su unilateralidad y coacción, aunque no es una simple aplicación de este derecho, dado que los espańoles encontraron a su llegada al Perú una cultura desarrollada.

- La imposición se da cuando a una comunidad se le conmina a obedecer y poner en práctica la legislación foránea, sin embargo, no es una mera aceptación de un Derecho penal extranjero, porque la sociedad nativa se rebeló al nuevo orden, que apreciaba en su represión rasgos de un derecho penal de autor.

- El Derecho Penal indiano tenía fuentes primarias y fuentes supletorias, aunque se presentó un primer Proyecto de Código peruano de 1635, estableciendo disposiciones penales en el sexto privilegio de su Libro Privilegial.

- La legislación penal peruana independiente fue un proceso complejo, que se entiende desde la resistencia del indígena en conservar sus normas consuetudinarias; hasta el esfuerzo del criollo que elaboró su propia legislación, considerando ilustrativa las disposiciones foráneas.

- La independencia del Perú no significó la libertad jurídica del país, pues el Derecho Penal criollo fue una ficción, en razón a que el Derecho Castellano de facto siguió vigente luego de 1821. En 1824 se castiga la delincuencia económica con pena de muerte, respecto al delito de contrabando. 
- La legislación penal del Perú independiente se aprecia desde el punto de vista nacionalista, indigenista revalorada, o impuesta libre para su elaboración.

- La República del Perú del siglo XIX, no borró la pro $\neg$ blemática existente entre el grupo dominante y el grupo explotado. Sin embargo, se promulgó el primer Código Penal peruano de 1863, por motivos técnicos legales y políticos criminales.

- La República del Perú del siglo XX, dio inicio a un nuevo esfuerzo en materia penal, y en la lucha contra los delitos económicos, promulgando el segundo Código Penal de 1924, y reformando el mismo, en un tercer Código Penal de 1991 vigente, aunque considerando los varios proyectos presentados con anterioridad

- La República del Perú del siglo XXI, propulsa mejorar la normatividad a través del informe final del anteproyecto del Código Penal 2008 - 2010, con la finalidad de adecuar los ilícitos al Estatuto de Roma de la Corte Penal Internacional; u otras normas que respondieron a los avances legislativos y jurisprudenciales, sobre todo las referidas a la delincuencia económica.

\section{REFERENCIAS}

- Basadre, Jorge. Los fundamentos de la historia del Derecho. Lima: Editorial Universitaria, 1967.

- Bramont Arias, Luis Alberto. Derecho Penal. Parte general. Tomo I. Lima:Talleres Litográficos de Villock S.A., 1972.

- Bramont Arias, Luis Alberto y Bramont - Arias Torres, Luis Miguel. Código Penal Anotado. Lima: Editorial San Marcos, 1995.

- Bramont-Arias Torres, Luis Miguel. Manual de Derecho Penal. Parte General. Lima: Editorial Santa Rosa S. A. 2000.

- De Leon Portocarrero, Pedro. Descripción del Virreynato del Perú. Lima: Editorial Universitaria de la Universidad Ricardo Palma, 2009.

- De Trazegnies Granda, Fernando. La idea de derecho en el Perú republicano del siglo XIX. Lima: Fondo Editorial de la Pontificia Universidad Católica del Perú, Segunda edición ,1992.

- Espino Pérez, Julio D. Código Penal. Lima: Editorial importadora Sevillana, Sexta edición, 1982.

- Galeano, Eduardo. Las venas abiertas de América Latina. Setenta y cinco ediciones. Buenos Aires: Siglo Veintiuno Editores, 2003. 
- El Inca Garcilaso de la Vega. Comentarios reales. "El origen de los Incas". Barcelona: Bruguera, 1968.

- Guamán Poma de Ayala, Felipe. Nueva crónica y buen gobierno, 2018. Link: http.//www.latinamericastudies.org/incas/Nueva_coronica_l.pdf.

- Halperin Donghi, Tulio. Historia contemporánea de América Latina. Madrid: Alianza Editorial, Tercera edición, 1972.

- Hurtado Pozo, José. La ley importada. Recepción del derecho penal en el Perú. Lima, Talleres de industrial grafica S. A. ,1979.

- $\quad$ Hurtado Pozo, José. Manual de Derecho Penal. Parte general I. Lima: Grijley, 2005.

- Jiménez de Asúa, Luis. Derecho penal en la República del Perú. Lima, Ediciones jurídicas, 1987.

- Leguía y Martínez, Germán. (s.f.) Diccionario de la legislación criminal del Perú. Lima: Librería e imprenta Gil S. A.

- Lumbreras Salcedo, Luis Guillermo. Pueblos y Culturas del Perú Antiguo. Lima: Ediciones Copé, tercera edición 2019.

- Mariátegui, José Carlos. Siete ensayos de interpretación de la realidad peruana. Lima: s.e.,1972.

- Matos Mar, José. Dominación, desarrollos y pluralismos en la sociedad y cultura peruana. En: Perú, actual (Sociedad y política), México, s.e., 1970.

- Momethiano Santiago, Javier Ysrel. "El indígena en la dogmática penal del siglo XIX". Lex, revista de la Facultad de Derecho y Ciencia Politica de la Universidad Alas Peruanas, número 10, año XI, Lima, Ediciones e impresiones Andina SAC, (2012): p. 309. https://doi.org/10.21503/lex.v10i10.224

- Momethiano Santiago, Javier Ysrael. Manual de Derecho Penal. Parte general. Lima: Editorial San Marcos, Segunda edición, 2016.

- Peña Cabrera, Raúl. Tratado de derecho Penal. Estudio programático de la parte General. Lima, Grijley, 1999.

- Rostworowski de Diez Canseco, María. Historia del Tahuantinsuyu. Lima: Instituto de Estudios Peruanos, 2014.

- $\quad$ Silva Vallejo, José Antonio. Filosofía del Derecho. Lima: Ediciones legales, segunda edición, 2012. 
- Sobrevilla, David. La filosofía del derecho en el Perú. Lima: Fondo Editorial de la Pontificia Universidad Católica del Perú, 2013.

- $\quad$ Stingl, Miroslav. El imperio de los Incas, esplendor y decadencia de los hijos del sol. Buenos Aires: Losada, 2013.

- Villa Stein, Javier. Derecho Penal. Parte general. Lima: ARA Editores, 2014.

- Villavicencio Terreros, Felipe Andrés. Diversidad Cultural y Derecho Penal. Lima: Ideas solución editorial, 2017.

RECIBIDO: 22/02/2021

APROBADO: 25/05/2021 